\title{
Using Simulation in an Industry of Gasket Products: A Case Study
}

\author{
Alexandre Magno Castañon Guimarães ${ }^{1} \&$ Madiagne Diallo $^{1}$ \\ ${ }^{1}$ Industrial Engineering Department, Pontifícia Universidade Católica do Rio de Janeiro, Brazil \\ Correspondence: Alexandre Magno Castañon Guimarães, Industrial Engineering Department, Pontifícia \\ Universidade Católica do Rio de Janeiro, Rua Marquês de São Vicente, 225, sala 950L, CEP 22453-900, Gávea, \\ Rio de Janeiro, Brazil. E-mail:alexcastanon@skydome.com.br
}

\author{
Received: August 28, 2012 Accepted: October 2, 2012 Online Published: October 26, 2012 \\ doi:10.5539/emr.v1n2p153 URL: http://dx.doi.org/10.5539/emr.v1n2p153
}

\begin{abstract}
This article presents a case study, in the gasket segment that approaches the use of Computer Simulation to identify inefficiencies in the use of resources in productive process flows and propose improvements. From the modeling scenes and with the demand data, it was possible to analyze the performance of the simulated processes flows, which allowed the help in resources management. For that, the fundamental concepts and aspects were approached, the main stages, the obtained results and the critical points as well. For this analysis the software Arena was used to elaborate the simulation models for the proposed case study.
\end{abstract}

Keywords: simulation, production, modeling, resources

\section{Introduction}

With the markets in constant evolution, the companies and organizations need to be always innovating themselves to have quality, flexibility, prices and time payment in their products and/ or services so they can be more and more compatible with the clients demands.

In this scene, it notices an increasingly competitiveness in the business environment, obligating the companies to make continuing efforts for the organizational and operational modernization and to search innovative solutions aiming more flexibility and reliability. These actions have, as a goal, guaranteeing the sustainability of meeting the clients' needs.

So, the great differential, for a company, is in the optimization of its operations, in other words, in the product capacity of arriving at the final client in the appropriate amount, in a fair price and according to the established deadline.

Therefore, the management process demands more and more the use of new technologies and methodologies to obtain an operational development increasingly efficient. So, it is a challenge the task of deciding, among the several available options, the ones which better achieve the goals, when they are related, for example, to the costs minimization, the quality improvement, the profits maximization, the layout optimization and the resources allocation, among others. So, it becomes beneficial the use of techniques that allow the administrators be sure that they are using a system that, if well administrated, can lead to several competitive advantages.

Among the suitable methodologies that are in the market, it can be mentioned the quantitative tools provided by the Operational Survey, that might help to understand the current structure and evaluate the consequences of the proposed actions and even identify the production sources based on the competitiveness, helping though, in the process of decision making (Hallgren \& Olhager, 2006). These tools can be approached by the deterministic models of mathematics programming or through the probabilistic models that consider the models uncertainty, such as stochastic programming, queuing theory and computer simulation.

For Sandanayake, Oduoza and Proverbs (2008) and Ekren and Ornek (2008), the use of simulation analysis of production systems for the development improvement has become increasingly important during the last decades. According to the researchers Banks (1998), Harrell, Bateman, Gogg and Mott (2000) and Law and Kelton (2000), the computer simulation has been a tool with great support potential to the decision making.

The main objective of this study is to apply computer based simulation tools to identify inefficiencies in the use of resources in productive flows and propose improvements. A case-based research methodology was chosen with the aim to provide an example of practice and test of the discrete event simulation in a manufacturing. The 
studied company acts in the gasket segment and due to confidentiality reasons, it will be called DELTA. The benefits of using computer simulation will be demonstrated by the optimization of the resources allocation through the modeled systems, guaranteeing attendance to the market in a lower cost. The obtained results and the critical points will be also discussed. In this work, the software Arena will be specifically used to construct the models of computer simulation for the study of the proposed case.

This paper is organized into five chapters, including this introduction. The second chapter includes some of the main theoretical foundations for the computer simulation. The scope of the third chapter discusses the case study. The outcomes and their analysis are described in the fourth chapter. Finally, the last chapter closes the paper with the conclusions of the research.

\section{Theoretical Foundations}

\subsection{Computer Simulation}

The use of computer simulation as a support to the decision making has allowed analyzing, systemically, the business unities. Law and Kelton (2000) affirm that the simulation has, as a benefit, obtaining a systemic vision of the effect that the local alterations can produce about the global development of the whole production system.

For the researchers McLean and Leong (2001), the simulation models are built to support the decisions about investments in new technologies, expansion of the production capacity, materials management, human resources and integration with the suppliers; in other words, through the simulation, it is possible to establish strategic goals of manufacturing.

The authors Sandanayake et al. (2008) highlighted that the simulation and the modeling help visualizing, analyzing and optimizing the complex production processes in a reasonable time before the complexity of the study and the investment.

\subsection{Simulation Application}

An example of the simulation technique use in future constructions was presented by Greasley (2008). The author developed and used a discrete event simulation modelto estimate the storage area necessary for a construction of a manufacture in the clothing industry.

Kalaoglu and Saricam (2007) also used the simulation in a modular production aiming studying the system productivity, varying the number of workers in a cell. They also found variations in the productivity when the number of workers is modified, but they don't distinguish the numerical flexibility (number of workers) and functional flexibility (variety).

The authors Ekren and Ornek (2008) analyzed and evaluated the effects of some process parameter in the development of a manufacture system. These parameters included two different types of plan layout - functional and cellular - and programming rules, machinery breaks, batches size and capacity of transporter as well.

In another research, Palominos, Quezada, and Moncada (2009) studied the response capacity of a production system before the demand variability in the clothing industry. For that, the system response capacity was modeled in function of the flexibility of work force resources and machinery.

\subsection{Computer Simulation Programs}

A meaningful development of simulation software that make the fast modeling of a particular environment easier has been lately increasing due to the great interest about this subject. This factor can be highlighted by the easiness of the use of software that are available in the market, where the screens of data input are guided by menus, reducing, significantly, the effort and the time necessary to the process of constructing a model. Besides, it can observe that these new environment are friendlier, statistically consistent and have graphic interface that allow visualization of simulations. Skills in computer programming, benefice though, aren't, any longer, indispensable. Another advantage in the use of these tools is that they present graphic animation and the output of statistic information that make easier the models critic (Barboza, 2006). The author mentions in her survey that the applicative can be classified in three categories:

(a) Programming language of general purpose, such as FORTRAN, C, C++ and Visual Basic among others;

(b) Programming language for specific simulation, such as GPSS, GPSS/H, SIMSCRIPT 11.5, MODSIM II, SIMAN V e SLAMSYSTEM

(c) Simulation package. This category includes many products that differentiate themselves according to their application, but that have characteristics in common. 
The choice of a simulation program, among the general purpose language software, programming language for specific simulation or simulation packages, is directly related with the connection between the user flexibility and specialization (Rodrigues, 1994).

There are several software programs in the computer modeling and simulation area. According to the literature, the most known are: Witness, Arena, Automod, Micro Saint, Extend, Quest, FlexSim and ProModel.

\section{Case Study}

\subsection{General Description of the Market Performance}

The company DELTA acts in the maintenance market and produces a type of product that, due to confidentiality reasons, will be called as Gasket Blanket. This material is used, generally, as a sealing element of fluids in various applications such as flanged joints, pipelines, industrial plants, sealing joints combustion engines, compressors, among others.

In the internal market, the company has clients in several segments, such as: automobile, steel industry, petrochemical, alcohol and sugarcane plant, among others. For the external market, the DELTA Company has clients, mainly for the industrial maintenance segment, located in the United States and Europe.

Due to strategic and confidentiality reasons, the names of clients / markets won't be revealed, being adopted the following nomenclature: Markets type I, II, III, IV and V, without jeopardizing the proposed study.

\subsection{Productive Process Description}

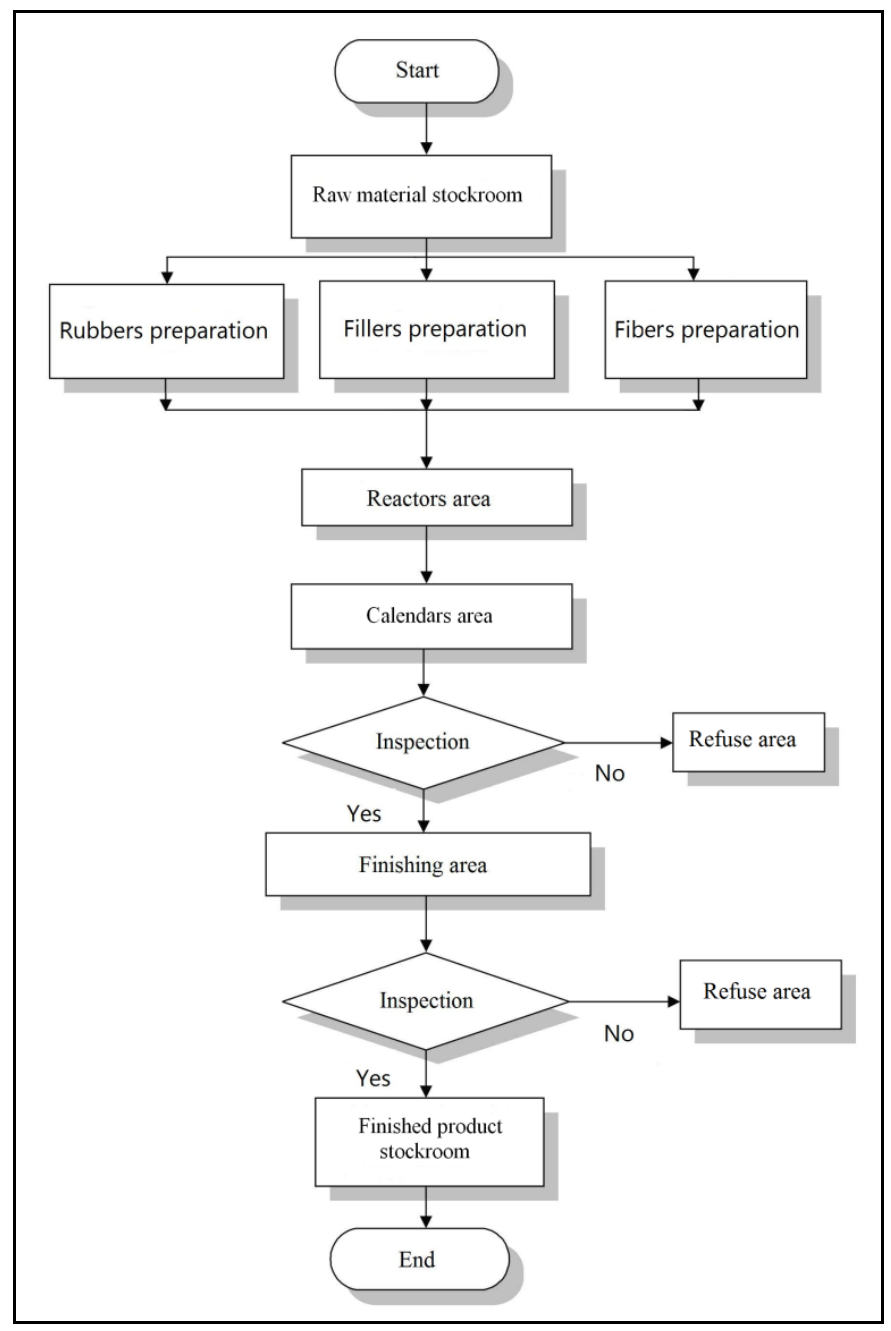

Figure 1. Flowchart of the gasket blanket manufacture process 
The necessary activities for the product processing are described in the Figure 1. The first step is the solicitation of raw materials to the stockroom, disregarding the purchase and storing process, since the supply is the responsibility of another unit. Thus, it was considered that the supply process has infinite capacity, i.e. there will always be raw material available for use.

Then, the raw materials are directed to the rubber processing, filler and fiber areas, where the respective kits are developed. The reactors area is where the mixtures are processed. The mixing operator searches for the rubber, filler and fiber kits and feeds the reactor according to manufacturing procedures. At the end of the processing time, the mixture is unloaded in a cart and is stored in the reactors area.

The transport of the mixture cart from the reactors area to the calendar area is done by the calendar operator. This area is where the production of Gasket Blanket occurs, being stored on moving tables and inspected. The material classified is then transported to the finishing area by the finishing operators, while the rejected material follows to the refuse area.

The finishing area is responsible for the cutting activities, application of non-stick and printing of the logo. A second inspection is also performed where the rejected material follows to the refuse area and the classified material is transported to the finished product stockroom (FPS), where it is stored for subsequent packaging in accordance with solicitations.

The unit under study operates in 3 shifts from Monday to Saturday. The preventive maintenance is always done on Sundays, so it will not be considered in this study. For strategic and confidentiality reasons, the actual productive capacity installed in the unit will not be disclosed. This does not undermine the proposed study, since the objective is to show the potential for the application of the computer simulation tool, offering the best scenario of machine / operator resources and flow of processes to meet the expected demand.

\subsection{Data Gathering for Simulation}

According to the authors Law and Kelton (2000), the simulation works with specific data of each process, also treating their abnormality and random. The data gathering for Harrell, Ghosh.and Bowden(2004) is one of the most important points of the simulation process, because, according to the authors, if the data aren't consistent the model also won't be.

For the modeling of this study, the averages' historic data and standard deviations that are used to program the whole unit were used. These parameters were obtained through a data rising, gathered during a period of 12 months in the rubber, filler and fiber preparation processes and in the reactor, calendars and finishing area, also being considered the data related to mental and physical fatigue, inefficiencies, preparations, meals and even physiological needs.

Table 1. Probabilistic distribution for the processes of gasket blanket manufacture

\begin{tabular}{llllll}
\hline Process & Market I & MarketII & MarketIII & MarketIV & MarketV \\
\hline Rubber & $\mathrm{N}(11,1)$ & & & & \\
Fiber & $\mathrm{N}(43,2)$ & & & & \\
Filler & $\mathrm{N}(11,1)$ & & & & \\
Reactor & $\mathrm{N}(100,4)$ & $\mathrm{N}(100,4)$ & $\mathrm{N}(100,4)$ & $\mathrm{N}(100,4)$ & $\mathrm{N}(110,5)$ \\
Calendar & $\mathrm{N}(160,5)$ & $\mathrm{N}(260,6)$ & $\mathrm{N}(140,4)$ & $\mathrm{N}(180,4)$ & $\mathrm{N}(160,5)$ \\
Finishing & $\mathrm{N}(8,1)$ & $\mathrm{N}(10,1)$ & $\mathrm{N}(8,1)$ & $\mathrm{N}(10,1)$ & $\mathrm{N}(8,1)$ \\
\hline
\end{tabular}

For the data analysis, the software Statgraphics Centurion was used and suggested a normal probabilistic distribution, $\mathrm{N}(\mu, \sigma)$, for the processes, according to Table 1, through Chi - Squared and Kolmogorov-Smirnov tests.

Even though, interviews were had with the process specialists (operators and engineers) to compare and validate these data. However, due to confidentiality reasons, the data presented in this chapter were corrected by a factor. This correction didn't change the study proposal and the simulations obtained don't show the factory reality, but demonstrate the possible alternatives of productive scenes, helping the managers in their analysis and decision making, which is according to the aim of this work. 


\subsection{Computer Simulation Model}

Demand data related to a period of a month for each market mentioned were used for reproducing the several scenes and estimate the respective results.

For the proposed modeling, the following was defined: Entities: rubber, filler and fiber; Resources: operators of each area, reactors and calendars; Queues: processes for rubber, filler, fiber, reactors, calendars and finishing.

The performance indicators used to evaluate the best scene of resources machines/ operators and process flow aiming to attend the demand were: the average time in queue (TF), in other words, the average time that an entity takes waiting in queue to be attended in a resource; the average use of resource (UR), expressed by the ratio between the time effective spent during the processing and the total time available; the total processed in each resource / process (TMP): of rubber, fiber, filler, reactors, calendars, finishing and the available total processed that got to the end of the system to enter in the stockroom of finished products. All the periods of time used in this modeling are in minutes.



Figure 2. Logic of the gasket blanket manufacture process

The logic of the modeling is represented in the Figure 2 by the simulation model of the softwareArena.

The preparation area of the rubber process is dimensioned for a shift with two operators. The fiber preparation area uses an operator in each shift, and it's grinding, weighing and storage of the fiber kits process is dimensioned for three shifts. In the filler preparation area, the same modeling as the rubber preparation is used.

For insuring that a kit of each entity goes to the reactor area, it was necessary to use the Mach and Bach modules. From this point, it is possible to consider this group as an entity.

In the reactors area, for insuring a balanced use of them, it was used the module "pickstation" with the lower value for the sum of amounts in queues, routes and resources. It was also created a single queue, with the aim of waiting the reactors release (Seize: PREPARATION), which capacity of mixture and junction of the three kits in this single queue gets conditioned to the amount of reactors necessary for attending the demand. This relation is of one mixture in the waiting for each reactor used. This area has an operator per reactor and works in three shifts.

For the calendar area, the module "pickstation" was also used with the same modeling of the reactors area. In this area happens the Gasket Blankets lamination, and it is dimensioned for working in three shifts of two operators per calendar. To characterize the inspection in this area, the module "Decide" was used with two options of probabilistic deviation, where the classified sheets follow to the finishing area and the unclassified ones follow to refuse area.

An important condition to be analyzed is that it only must initiate the process in a reactor when the previous mixture has entered into the calendars area. It is done to avoid that the mixture stays more than four hours in queue, avoiding though, an early vulcanization. This condition lead to the creation of a single waiting queue 
(Seize: MIXTURE) before entering the calendar area. The mixture capacity in this queue gets dependent on the amount of calendars necessary for the demand attending. This relation is of a mixture in waiting for each calendar used.

The cut, application of non stick surface and logo print process performed in the finishing area happen in a shift with four operators. In this area is where occurs also a second inspection, characterized by the module "decide" that follows the same purpose of the calendar area where the unclassified material goes to scrap and the classified one is transported to the finished products stockroom, where it gets stocked for further packaging according to the orders requirements.

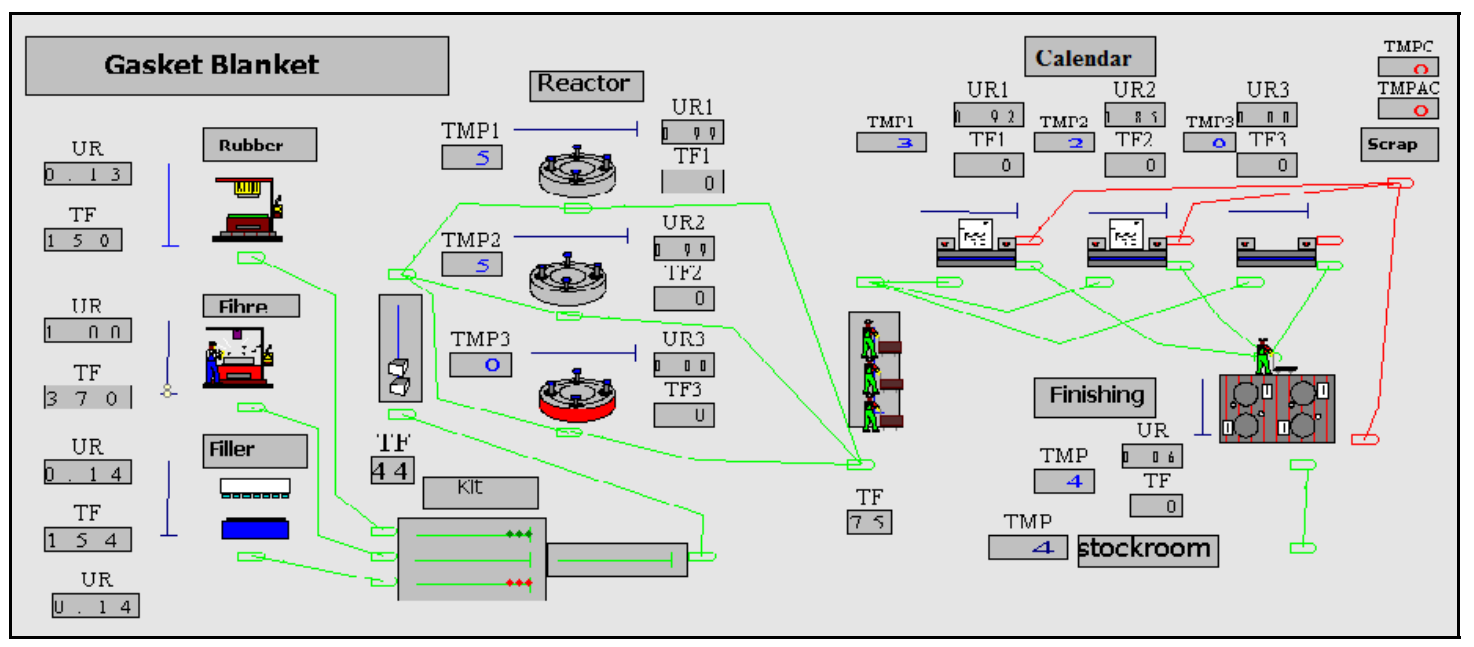

Figure 3. Illustrative representation of the animation for the gasket blanket manufacture

The proposed modeling animation containing the resources, entities, processes, queues and the performance indicators is illustrated in the Figure 3.

\subsection{Original Scene}

Table 2. Original structure to attend the demand of the studied period

\begin{tabular}{lcccc}
\hline Process & ProcessesAmount & \# Shift & \# of operators by shift & Total of operators \\
\hline Rubber & 1 & 2 & 2 & 4 \\
Filler & 1 & 2 & 2 & 4 \\
Fiber & 2 & 3 & 1 & 6 \\
Reactor & 6 & 3 & 1 & 18 \\
Calendar & 8 & 3 & 2 & 48 \\
Finishing & 1 & 1 & 4 & 4 \\
\hline
\end{tabular}

Table 2 shows the structure indicated by production to meet demand studied.

Through analysis of the performance indicators and distributions mentioned before, it is possible to verify the inactivity and/ or excesses for each area and propose the best scene for the resources allocation for each market.

In the following, the analysis and the proposals of the best resources allocations for each market type aiming the demand attending will be presented.

\subsubsection{Market I}

For this analysis the demand data of $83620 \mathrm{Kg}$ was considered. As each mixture has an average weight of 220 $\mathrm{Kg}$, it will be necessary that, in the end of the period, it has been processed the equivalent of 381 mixtures (TMP) 
for the finished product stockroom. The profits of $95 \%$ and $98 \%$, respectively, in the calendar and finishing area regarding the inspection were also pondered.

For the preparation of the rubber, filler and fiber processes were used 25 arrivals of 17 entities, with a break of 1440 minutes between each arrival, for each one of these processes.

Through the analysis of the performance indicators and of the distributions mentioned before, the most indicated scene for this market is formed by two reactors and two calendars.

With basis on the indicatives, it can be observed the existence of inactivity in the rubber, fiber, filler and finishing area, with the URs of $0.13,0.51,0.13$ and 0.09 respectively, indicating the possibility of absorbing other markets. In the reactors area, although it also observes inactivity for the two reactors with the UR performance indicator of 0.62 and 0.56 , it wouldn't be possible to process this total of mixtures in only one reactor, because it would exceed the available total time. It can better use the relation number mixture operator per reactor, though. Another possibility would be to use the available time to produce other markets mixtures. In the case of the calendars area, two calendars are enough to attend the market I demand with the URs of 0.96 and 0.94 , demonstrating that practically the whole available time is already being used. The average time of waiting for attendance (TF) in the single queues of the reactors and calendars areas, were of 58 and 225 minutes, respectively. The final TMP performance indicator of this modeling to input the APA was equivalent to 399 mixtures, which is above the minimum forecasted, 381 mixtures, attending, without problems, the demand for this market.

\subsubsection{Market II}

For this market, it was considered the sale data of $65370 \mathrm{~kg}$. As each mixture has an average weight of $220 \mathrm{~kg}$, it will be necessary that, in the end of the period, the equivalent of 298 mixtures for the stockroom of finished product has been processed.

This market presents the worst outputs in the calendars and finishing areas regarding other markets. The inspection presents data of $88 \%$ and $92 \%$ respectively. The great demand of this market, with more strict specifications and operational difficulties in the manufacture of the products lead to this data.

For the preparation area of the rubber, filler and fiber process, 25 arrivals of 15 entities were used, with a break of 1440 minutes between each arrival for each one of these processes.

With the probabilistic distributions of Table 1 and with the analysis of the performance indicators, it verifies that the modeling proposed for this market suggests a scene composed of two reactors and three calendars.

Just like Market I, it's possible to realize that the rubber, filler, fiber and finishing areas easily attend the demand with URs of $0.11,0.45,0.11$ and 0.09 respectively. With the existent inactivity it can, for example, to absorb other markets. In the reactors area, although it's possible to observe inactivity for the two reactors, URs of 0.55 and 0.49 , it wouldn't be possible to process this total of mixtures with only one reactor, because the same way as Market I, it would exceed the available time. It's also possible to observe the possibility of better use the relation number of mixture operator per reactor or use them again to observe the demand of other markets.

For the calendar area it would be necessary three calendars to attend the Market II demand, with the UR performance indicator presenting 0.90 for the three of them, however, it can for example, use this availability of 0.10 to manufacture the make to stock products.

It's possible to observe for this modeling the time for single queues were of 49 and 219 minutes for the reactors and calendar areas, respectively. The final TMP performance indicator was of 300 mixtures, a little above the demand data that is equivalent to 298 mixtures.

\subsubsection{Market III}

The sales data used for the Market III was of $55950 \mathrm{~kg}$. As each mixture has an average weight of $220 \mathrm{~kg}$, it will be necessary that, in the end of the period, it has been processed the equivalent to 255 mixtures for the finished product stockroom. The inspection in these calendar and finishing areas presents output data of $92 \%$ and $99 \%$, respectively.

In the preparation area of the rubber, filler and fiber processes, 25 arrivals of 11 entities were used, with a break of 1440 minutes between each arrival, for each one of these processes.

The proposed modeling for this market, having the probabilistic distributions mentioned on Table 1 and the performance indicators as a basis, suggests a scene composed of one reactor and two calendars. 
The inactivity is observed again in the rubber, filler, fiber and finishing areas according to what was presented in the UR performance indicator of $0.08,0.32,0.08$ and 0.06 , respectively, signalizing, again, the possibility of absorbing other markets.

In the reactors area, even with only one, it still has the UR of 0.76 of use, which again, suggests the possibility of absorbing the other markets' products. In the calendars area case, the indicators show that one calendar wouldn't have the capacity to attend the whole Market III, as it would have a UR indicator higher than 1, therefore it is necessary to use two calendars with URs of 0.59 and 0.49 . A suggestion to optimize this situation would be, for example, using a calendar dedicated to this market and a fraction of another calendar dedicated to another market during this time. The waiting time was of 293 and 0 minutes for the single queues of the reactors and calendars areas, respectively. For this market, the final TMP was of 252 mixtures. It observes that it is below the minimum for this market, which needs 256 mixtures. Although, as in the previous market, the TMP is above their respective minimums of mixture, it verifies that this difference can be absorbed in another market. Other possibility is that this difference be produced in this same market, due to the URs already mentioned.

\subsubsection{Market IV}

For the Market IV, the sales data of $28400 \mathrm{~kg}$ was used. As each mixture also has an average weight of $220 \mathrm{~kg}$, it will be necessary that in the end of the period the equivalent to the minimum of 130 mixtures have been processed for the finished product stockroom. The inspection in the calendars and finishing areas reports data regarding the profits of $90 \%$ and $95 \%$, respectively.

For the preparation area of the rubber, filler and fibers processes, 25 arrivals of 6 entities were used, with a break of 1440 minutes between each arrival, for each process.

The analysis of the performance indicators demonstrates to be the scene of one reactor and one calendar, the most indicated for this market.

For the rubber, filler, fiber and finishing areas, that present the performance indicator, UR of 0.04, 0.18, 0.04 and 0.04 , respectively. Again, it observes that these areas easily attend the forecasted demand. In the reactors area, even using only one, it realizes that its occupation isn't total with the UR of 0.75 , what suggests again, the possibility of; for example, use it in the manufacture of other markets' products. The same thought is regarding the calendar areas that, with only one, have the UR of 0.59. It's also important to emphasize that for the reactors and calendar areas, the TF performance indicator for single queues was of 348 and 0 minutes, respectively. The TMP obtained in the end of the process was equivalent to 133 mixtures, a little higher than the demand data which is equivalent to 130 mixtures.

\subsubsection{Market V}

For the analysis of the Market $\mathrm{V}$, it was used the demand data of $12790 \mathrm{Kg}$. In this market, differently from the others, the average weight of each mixture is of $150 \mathrm{Kg}$. So, it will be necessary that, in the end of the period, it has been processed a minimum equivalent to 86 mixtures for the finished product stockroom. In the calendar and finishing areas, the profit data of $94 \%$ and $98 \%$ regarding to the inspection were used, respectively.

The preparation area of the rubber, filler and fiber processes used 25 arrivals of 4 entities, with a break of 1440 minutes between each arrival, for each case.

Analyzing the performance indicators of this market, it comes to the conclusion that the best scene to the allocation of resources is of one reactor and of one calendar.

The Market V's resource allocation is alike Market IV's. The performance indicators present the rubber, filler, fiber and finishing areas, again with inactivity and available to attend other markets, according to data demonstrated in the UR performance indicator of $0.03,0.12,0.03$ and 0.02 , respectively. In the reactors area, even using only one of them, it's possible verifies that its occupation is not complete; it has the UR of 0.30 , what suggests that it can be used for other products, as for example, absorbing the products of Market IV. The same, though, is regarding the calendar areas that, with only one of them, has an occupation of 0.44 and also can, for example, be used to produce the Market III's products. The TF performance indicator of single queues was of 102 and 75 minutes for the reactors and calendar areas, respectively. The final TMP for this market was of 91 mixtures that easily satisfy the demand that is equivalent to 86 mixtures.

\section{Results}

The verification and validation of the proposed modeling are of extreme importance for the analysis of the presented results. Adjusted historic data of the Gasket Blanket factory was used for this work development. Besides, during all the modeling work, it verified the participation of this process' specialists, contributing with 
their considerations. One of the methods presented in the literature for the modeling validation is of the authors Harrell et al. (2004) that consider being indispensable the existence of involvement, as of the people who know the system to be modeled as of those who will make decisions during the model development. So, besides the correction made in the historic data, the modeling was considered valid by the specialists of the area as they didn't present any discrepancy regarding the existent productive flows. Another factor that contributed for these models validation was the possibility of viewing the processes flows, obtained with the software Arena, also contributing for this project's specialists and participants analysis.

With the proposed modeling, it was possible to verify for each process, the limitations and inactivity in their capacities and also their main queues and their use, making possible to identify line bottlenecks and imbalances. With this information, it is possible to previously react to the demand variations proposing solutions that optimize the resources and attend the needs of each market.

It can also verify that, with the help of the computer simulation tool, it is possible to optimize the allocation of the operators. For example, considering the analysis made for the five markets presented, it is possible to obtain the occupation time of each process. From these values, it determinates the amount of processes necessary to attend the demand of the studied period, considering 21 hours worked in three shifts a day.

Table 3. Proposed structure to attend the demand of the studied period

\begin{tabular}{lccccc}
\hline Process & Occupation time $(\mathrm{h})$ & Processes Amount & \# Shift & \# of operators by shift & Total of operators \\
\hline Rubber & 9.36 & 1 & 2 & 2 & 4 \\
Filler & 9.36 & 1 & 1 & 2 & 2 \\
Fiber & 40.30 & 2 & 3 & 1 & 6 \\
Reactor & 96.72 & 5 & 3 & 1 & 15 \\
Calendar & 161.04 & 8 & 3 & 2 & 48 \\
Finishing & 7.20 & 1 & 1 & 4 & 4 \\
\hline
\end{tabular}

According to Table 3, it is possible to present an allocation proposal of operators, aiming to try optimizing the line keeping the relation of operators per process already existent in the unity.

The data indicates inactivity in the occupation periods for the rubber and filler areas, with 9.36 hours in each process for two occupation shifts. This imbalance might be bypassed improving the operators' allocation, for example, in a shift, the operators are dedicated to their respective areas and in other shift, and the rubber process operators can absorb the filler process activities. So, it recommends four operators, two in each shift in the rubber area and two operators, in one shift, in the filler area.

For the finishing area, it verifies that only one shift won't be enough to attend the demand. This difference is of 0.2 hours and can be absorbed by the operators on a break from other areas, as for example, the reactors area. So, one shift can be kept with four operators.

In the fiber area it observes that it is necessary an occupation time of 40.30 hours. It means that this area won't be capable of attending the ordered demand, even working in three shifts. So, two fiber processes with three shifts will be necessary, totalizing six operators.

Using the same analysis for the reactors and calendar areas, it verifies that the reactor area needs to have five processes operating in three shifts; as a result, it recommends five operators per shift. The calendar area needs eight processes operating in three shifts, what suggests two operators per calendar per shift, totalizing forty eight operators.

Another factor to be detected is the possibility of a company previously knowing the availability for the manufacturing of make to stockproducts and then choosing which strategy is the best one to be adopted, through the production planning.

\section{Conclusion}

This work approached the application potential of computer simulation supporting making decision. The modeling was made from a productive unit of this case study, using for that, the software ARENA. This modeling allowed proposing several scenes, which results were analyzed to guarantee the best resources 
allocation to attend the forecasted demand. The analysis made possible to visualize the respective limitations, inactivity and capacity of each process, identifying bottlenecks and line imbalance. From this information, it was possible to propose solutions that improve the resources, making the company leaner and efficient, to attend the variations of demands.

Considering the analysis for the current scene in section 3.5, was presented a proposal for allocation of resources to improve the balance of the line, keeping the relationship of existing processes by operators. The result of this analysis presented in section 4 with the reduction of a shift in the filler process, reduction from 6 to 5 rector processes and the decrease of 5 players on the line as shown in Table 3, with the immediate consequence of a reduction in maintenance costs, utilities and labor. These changes improve the efficiency of the line and did not affect the final volume required to meet demand.

Another benefit observed with the use of computer simulation that is really useful for the company to know was that with the application of the modeling proposed, it is possible tohave a systemic view of the effects that alterations in the process will have on the global performance of the production flows, making possible the creation of future scenes without the necessity of real investments. So, the one responsible for making decisions can know the consequences of actions, allowing a better evaluation of the logistic systems and having, as a consequence, more efficiency in the resources use, in the reduction of intermediate and final stocks, lower operational costs, among others.

The accessibility of the information obtained through a detailed simulation model can valid and makes the decision process easier and also motivate the organization to obtain the desired results.

\section{References}

Banks, J. (1998). Handbook of Simulation: Principles, Methodology, Advances, Applicatios and Practice (1st ed.). John Wiley and Sons, New York, NY.

Barbosa, A. O. (2006). Simulação e técnicas da computaçãoevolucionária aplicadas a problemas de programação linear inteira mista. Tese de Doutorado, Programa de Pós-Graduação em Engenharia Elétrica e Informática Industrial, Universidade Tecnológica Federal do Paraná.

Ekren, B. Y., \& Ornek, A. M. (2008). A simulation based experimental design to analyze factors affecting production flow time. Simulation Modelling Practice and Theory, 16, 278-293. http://dx.doi.org/10.1016/j.simpat.2007.11.016

Greasley, A. (2008). Using simulation for facility design: A case study. Simulation Modelling Practice and Theory, 16, 670-677. http://dx.doi.org/10.1016/j.simpat.2008.04.009

Hallgren, M., \& Olhager, J. (2006). Quantification in manufacturing strategy: A methodology and illustration. International Journal of Production Economics, 104, 113-124. http://dx.doi.org/10.1016/j.ijpe.2005.09.004

Harrell, C. R., Bateman, R. E., Gogg, T. J., \& Mott, J. R. A. (2000). System Improvement Using Simulation (1st ed.). McGraw-Hill.

Harrell, C. R., Ghosh, B. K., \& Bowden, R. (2004). Simulation Using ProModel (2nd ed.). McGraw-Hill.

Kalaoglu, F., \& Saricam, C. (2007). Analysis of modular manufacturing system in clothing industry by using simulation. Fibres \& Textiles in Eastern Europe, 15(62), 93-96. Retrieved from http://www.fibtex.lodz.pl/62_21_93.pdf.

Law, A. M., \& Kelton, W. D. (2000). Simulation Modeling and Analysis (3rd ed.). McGraw-Hill.

McLean, C., \& Leong, S. (2001). The Role of Simulation in Strategic Manufacturing. International Working Conference on Strategic Manufacturing, 239-250.

Palominos, P., Quezada, L., \& Moncada, G. (2009). Modeling the response capability of a production system. International Journal of Production Economics, 122, 458-468. http://dx.doi.org/10.1016/j.ijpe.2009.06.020

Rodrigues, L. H. (1994). Developing an approach to help companies synchronise manufacturing. Tese de doutorado. Departament of Management Science University of Lancaster.

Sandanayke, Y. G., Oduoza, C. F., \& Proverbs, D. G. (2008). A systematic modelling and simulation approach for JIT performance optimization. Robotics and Computer-Integrated Manufacturing, 24, 735-743. http://dx.doi.org/10.1016/j.rcim.2008.03.013 